\title{
Counselors' Experiences Using Sandtray Therapy for Recovery Adolescents
}

\author{
Anas Zulhifzi Buang ${ }^{1}, \mathrm{Ku}$ Suhaila Ku Johari ${ }^{1 *}$, Zuria Mahmud ${ }^{1}$, Dharatun Nissa Puad \\ Mohd Kari ${ }^{1}$, Salleh Amat ${ }^{1}$
}

${ }^{1}$ Universiti Kebangsaan Malaysia, Bangi, Malaysia

*Corresponding author. Email: suhaila@ukm.edu.my

\begin{abstract}
Sandtray therapy is an approach in counseling field. This approach uses play as a method for client to express their emotion, thought, behavior and experience related to the issue of their problems. The objective of this study is to explore the counselor's experience using sandtray therapy approach in group counselling for adolescent-substance abuse client's on early recovery. An interview was conducted to four facilitators who have been trained using sandtray therapy. There was 32 adolescents who on early recovery involved as clients substance abuse. The thematic process was used to explore their experience of conducting group. Counselling using sandtray therapy approach. The finding shows that the sandtray approach enable the counselor's to explore issues among clients. Thus, the counseling process was processed effectively. This study also found that the client's dialect was the limitation of the study. Follow-up study is suggested for further research to explore the client's experience during early recovery intervention.
\end{abstract}

Keywords: Sandtray therapy, counselor, recovery, adolescent

\section{INTRODUCTION}

Counselling is a profession in the domain of Helping Professionswhich involves two partiesof clients and counsellors and are subjected to the prescribed acts and ethics. Counselors are professional individuals who have qualifications recognized in practicing counselling. A career in Counselingis a career that needs to face various issues and problems that are increasingly challenging from time to time. With the advancement and circulation of the ever-expanding era, a counselor's career becomes an important requirement in maintaining the continuity of human capital from generation to generation. Along with the changing times that undoubtedly invite various pressures from every angle of life, a counsellor must also prepare themselves with high skills and have the competence to cope with the needs of diverse clients in order to achieve the well-being of the community.

Drug addiction counseling focuses on the collection symptoms and aspects related to the individual's psychosocial function affected by the accumulation and continuity of the content and structure of the recovery program. It emphasized behaviour change by providing coping strategies and tools for recovery to clients. It is therefore the responsibility of the counsellor to understand and help them learn new skills by giving hope to be motivated in order to change. The recovery becomes less effective if we just tell the client about himself or what should be done, unless the client comes up with a basic understanding to change in the way he thinks (Lasimon, 2007).

Sandtray is an expressive and projective mode of psychotherapy involving the unfolding and processing of intra- and inter-personel issues through the use of specific sandtray materials as a nonverbal medium of communication, led by the client or therapist and facilitated by a trained therapist. It is a process that seeks to promote safety and control for the client so that emotionally charged issues can be addressed through the medium (Homeyer\& Sweeney, 2016).

Sandtray therapy involves a miniature selection process by clients, arranging miniatures within the sandtray and storytelling by clients. Counselors use counseling skills to explore, document, assist and transmit the client's world. Various counseling theories such as Adler's theory, client centering and Gestalt theory can be integrated with the sandtray for clients to acquire a sense of literacy (Nur ShakilaIbrarim\& Ku Suhaila Ku Johari, 2015).

Research on play therapy was done by Gooh Mo Lee $\& \mathrm{Ku}$ Suhaila (2018) to identify the effect of sandtray therapy towards the improvement of the five self-esteem variables: general, social, family, academic, and lie. The finding showed there is a significant effects of sandtray therapy that can be seen in the self-esteem variables 
between the pre-test and post-test results of the experimental group. The findings of this study also support previous literature which indicated that sandtray has been beneficial in helping children in developing their self-esteem.

Monakes et al. (2011) conducted a counseling session with drug addicts using sandtray therapy to gain an understanding of the perceptions and experience of drug addicts on cognitive treatment of client behavior. The participants reported that they had a positive experience through the treatment of sandtray therapy. Ramsey (2014) notes that sandtray therapy is an effective approach to cross-cultural counseling as it provides a space for cultural and client-centered multi-cultural experience. Research findings for all three study participants also found that sandtray therapy can help clients identify and express emotions and help clients build new thinking on client confidence.

Among the interventions in counseling that have been done are the 7 Steps of Recovery when researchers look at the importance of religious modules in assisting the treatment of drug rehab, then the study on the construction of a quality religious module is desirable. Therefore, this 7-Step recovery module is undertaken as an effort to provide counseling and motivational assistance to clients as a continuation of the religious module conducted at the Cure and Care RehabilitionCenter (CCRC) in Malaysia. This module has been prepared by the concept of Tazkiyat al-Nafs alGhazali as a model. Facilitators who conduct the group consist of counselors, peer counselors (PRS), and officers of the National Anti-Drug Agency (AADK) who have been trained using the 7-step recovery module. Each member must pass through 10 sessions contained in this module (Mohamad Isa et.al, 2018).

In addition, there are researchers studying using the Interventions of Behavioral Cognitive Therapy on Changed Readiness and Self-Esteem. The effectiveness of rehabilitation and treatment of drug addicts in rehabilitation institutions is closely related to psychological changes before they are interpreted to the form of behavior. Behavioral Cognitive Therapy (CBT) is a means of recovery based on psychological treatments involving the focus, feelings and behaviors that focus on the problem. Therefore, it is a method of change to thinking before being transferred to a form of behavior consistent with the change of thought in the environment. Six sessions were conducted in this intervention and each session was different from the training aspect but had the same goal for drug rehabilitation. Therefore, this study aims to explore the counselor's experience of conducting group sessions using a sandtray therapy approach in addiction counseling. (Noor AznizaIshak et.al, 2013).

\section{METHOD}

\subsection{Research Design}

This study is a qualitative study of case study design. Yin (1994) explains the case study approach needed to help researchers explore and understand complex issues in which case study approaches are able to examine and explore a phenomenon. In the context of current studies focusing on exploring the counselor's experience in conducting group counseling sessions using a sandtray therapy approach. Merriam (2009) suggests for a case study, researchers need to determine clearly what to look at.

\subsection{Participants of the Study}

Participants of the study involved four counselors who had been trained using the modules they had built and they had the basic skills of using sandtray therapy approaches in group counseling among teenage drug addicts early in life.

\subsection{Data Collection and Analysis}

The data were obtained through group interviewing methods. Interview questions are provided based on literature review and reviewed by experts. The data were analyzed with a thematic process of examining the recording transcription and identifying themes that arose based on the objective of the study.

\subsection{Module}

Built-in modules include several sub themes for exploring personal, family, friends, billing world, career interests, spiritual, support system and dream world. This module is conducted for six sessions and each session takes 1 hour and 30 minutes. Sandtray therapy is carried out based on five implementation protocols, namely: 1 . Provide space equipped with sand tray equipment, 2 . Introduce sand tray to client, 3. Build picture in sand tray, 4. Sand-related partnership and tray, 5. Termination and clean the sand tray and 6. Document the session through counseling reports (Homeyer\& Sweeney, 2016).

2.5. Module Summary

\begin{tabular}{|c|l|l|}
\hline $\begin{array}{c}\text { Sub } \\
\text { Module }\end{array}$ & Activity & \multicolumn{1}{|c|}{ Activity Summary } \\
\hline $\begin{array}{c}\text { One } \\
\text { Adventur } \\
\text { e }\end{array}$ & $\begin{array}{l}\text { Build Self } \\
\text { Relationship }\end{array}$ & $\begin{array}{l}\text { Build relationships } \\
\text { between counselors and } \\
\text { clients through } \\
\text { restructuring and } \\
\text { reporting. Sharing and } \\
\text { exploring to identify } \\
\text { and identify the } \\
\text { advantages and } \\
\text { disadvantages of self } \\
\text { through self-portrayal } \\
\text { within the sand tray. }\end{array}$ \\
& & $\begin{array}{l}\text { This sub module serves } \\
\text { to recognize and } \\
\text { explore family systems }\end{array}$ \\
\hline $\begin{array}{c}\text { Roots, } \\
\text { Branches } \\
\text { and }\end{array}$ & Family & \multicolumn{2}{|c|}{} \\
\hline
\end{tabular}




\begin{tabular}{|c|c|l|}
\hline Twigs & Friend & $\begin{array}{l}\text { and friends as well as } \\
\text { understand the meaning } \\
\text { of family and friendship } \\
\text { value. }\end{array}$ \\
\hline $\begin{array}{c}\text { Dead } \\
\text { End }\end{array}$ & $\begin{array}{c}\text { Addiction } \\
\text { World }\end{array}$ & $\begin{array}{l}\text { Sharing and exploring } \\
\text { the experience of the } \\
\text { world of billing and } \\
\text { how they engage with } \\
\text { the world of addiction }\end{array}$ \\
\hline $\begin{array}{c}\text { Searchin } \\
\text { g for the } \\
\text { Horizon }\end{array}$ & $\begin{array}{c}\text { Career } \\
\text { Interest } \\
\text { is with } \\
\text { me }\end{array}$ & $\begin{array}{l}\text { Morals and } \\
\text { Divine \& } \\
\text { Support } \\
\text { their career interests }\end{array}$ \\
Systems & $\begin{array}{l}\text { Explore and understand } \\
\text { the value of the existing } \\
\text { spirituality and the } \\
\text { supportive system in } \\
\text { life. }\end{array}$ \\
\hline $\begin{array}{c}\text { The new } \\
\text { Me }\end{array}$ & $\begin{array}{l}\text { My } \\
\text { Dreams }\end{array}$ & $\begin{array}{l}\text { Help to build new } \\
\text { expectations, feelings } \\
\text { and thoughts for the } \\
\text { future. }\end{array}$ \\
\hline
\end{tabular}

\section{FINDINGS}

There are several themes that can be released in this study: 1) Relationship between counselor and client in using sandtray therapy in addiction counseling. 2) Advantage of sandtray therapy approach in addiction counseling. 3) Interaction and group dynamics use a sandtray therapy approach in addiction counseling. 4) The client's progress during the sandtray therapy session. 5) The challenge faced by counselors using the sandtray therapy approach in addiction counseling.

Theme 1: Relationship between counselor and client in using sandtray therapy in addiction counseling.

Based on interviews, this theme shows that counselors find that relationships can be easily constructed as there is no objection from early adolescent early recovery. This is due to the nature of sandrays therapeutic approach, because it is a natural language for children and adolescents. Indirectly the client is more secure and not threatened. This approach also does not depend on cognition and makes the discharge better than the client. The counselor states that clients who are excited about this approach as well as the toys that are there because it is something new for them to give a positive impact to the counselor to continue the session using the sandtray therapy approach.

The counselor stated that the client gave a good response and then launched a session trip. Counselors can build good relationships with all clients. The response received from the client is very quick and indirectly they understand the issues experienced to make counselors more comfortable using this approach throughout the session
All counselors emphasize this theme. Among the statements given by the counselor are "the study participants respond very well ... and from there we see them welcoming, they are excited about our presence and with the approach we use them they feel something new is something that can help they are to express feelings ".

Theme 2: The advantages of sandtray therapy approach in billing counseling.

The counselor noted that there are several advantages of the sandtray therapy approach that has been used. There is a difference with the conventional counseling previously used. This approach not only uses verbal but also uses diverse sensors such as touch and vision senses. This allows the client's learning process to deal with the problem and the process of exploring the counselor on client issues will become more clear and effective. The counselor can understand what a client is sharing through the selection of games, arrangements and illustrations given, so the counselor can help the client achieve their goals.

The counselor feels that the client is excited about the games that will make them enjoy sharing about the chosen miniature. This is due to the provision of miniatures that take into account all the categories contained in sandtray therapy as well as the provision of specialized miniature for the study population according to the module provided. This miniature diversity allows clients to express their feelings, thoughts, and experiences effectively.

All counselors also agree with this. Examples of statements given by the counselor are: "The reason $I$ think the sandtray is very helpful especially in children. Because their children's clients are hard to understand and with the help of their sandtray it is easier to express".

Theme 3: The interaction and group dynamics within the session using the sandtray therapy approach.

Interaction and dynamics are an important foundation in the group counseling process. The counselor noted that there was a difference between clients who entered the Cure and Care clinic voluntarily and by court order. At the beginning of the session, the voluntary client initiated it by responding well and encouraged other clients to share and respond to other members of the group. Counselors also see clients respond well to conversations, give ideas, express, issue and view their issues due to their mature attitude. Among the factors causing them to mature is due to the age and environment of the rehabilitation center.

The sandtray therapy approach from the counselor's opinion also helps the group's experts to better understand the other group's expertise. Each member feels easy to understand another member's issue through the description of the built-in sandtray. Their focus on 
sharing is good as they are able to understand clearly about the feelings and depictions of other members of the group. They are also motivated by curiosity when they can compare their sandrays' pictures with other members because of the differences in imagery through the arrangement and selection of toys to help each member become more closely and empathy. Counselors also feel the dynamics in the group work well when clients give their opinions without any hindrance and shame. He indirectly made the relationship of all the members of the group more sticky.

All counselors agree on this theme and think that the session is being held strong dynamics among all group members through statements. Examples of statements are "The dynamic in the group is very ok. Because when we ask, they give each other their opinions and they are easy to interact because the playing medium makes it easy for them to interact and not feel difficult to understand. "

\section{Theme 4: The development of clients during a sandtray therapy session.}

During the course of the session, the counselor sees the emotional development is positive throughout the session, especially when the client shares the family. The feeling of client's longing for the family and the feeling of regret for clients when trapped by drugs. This is because the client sees the picture of their family through the chosen miniature. They feel like the family is close to them. There are several clients through co-counselor sharing, they depict angry and disgusting emotions when attending a recovery program at the Cure and Care clinic through selected miniatures. At the end of the session, there were changes and their angry feelings became diminished with the help of counselors who made them more rational.

Counselors can also see the cognitive developments that occur from clients. The change in the way negative thinking is positive for the sake of goodness and advantages are in Cure and Care clinics. Sandtray helps clients to realize the detrimental effects of drugs that will lead to other problems.

From the perspective of behavioral development, counselors are aware at the beginning of the client's session are rather shy to share with counselors even more in the group. The counselor strives to build relationships and trust between counselors and group members. Members of the group later became more comfortable sharing publicly with group members. Counselors say clients are also more clever in using existing miniatures to brag about their feelings.

All counselors agree with emotionally related statements because they get the same emotionally client that is "Like me, I like the reason they first told me why they can get involved with drugs and their emotions are being missed by the family, remembering how they are with drugs. So their emotions are unstable. But when it comes to their own, they can be summarized in divine sessions. That is, they are more obvious with what they want. And their emotions on the divine concept are very positive."

Theme 5: Challenges faced by counselors using sandtray therapy approaches in addiction counseling. Among the challenges faced by counselors in conducting group sessions using the sandtray therapy approach is the first perception of the counselor before commencing a session with a client comprising teenage drug dependents. The counselor once pointed out that the thing a drug addict would tell is totally unbelievable. The perception changes when the counselor starts the session because the client is in good condition.

Additionally, counselors are of the opinion that having good knowledge and skills in sandtray therapy can help the counselor explore the client better. The counselor considers at the beginning of the session, the counselor has a tendency to put the meanings for the miniature that the client has chosen. After that the counselor realizes the meaning of every minute is not the same as the other individual because of the different definitions and perspectives. Kaunslor needs to explore best for each miniature that clients have chosen to get a more accurate picture

Another challenge faced by counselors is understanding the themes of the billing world. Among them are the types of drugs and their effects on clients. This is because every client takes different types of drugs. The counselor should have knowledge about the type of drugs and the effects on the addicts. At least this knowledge can help more effectively in understanding their addictive world

All counselors acknowledge good knowledge and skills in sandtray therapy as well as knowledge in billing counseling are essential to be empowered to become effective counselors. These are some of the challenges they face. Among the statements related to the perception of counselor is that "I need to get training and learn more about sandtray therapy and billing counseling because this factor helps me as a counselor can help more effectively."

\section{DISCUSSION}

Studies show that the use of sandtray therapy approaches in group counseling among adolescent adolescent drug addicts in early recovery, focused and focused sandtray exploration therapy can help facilitate the exploration process of clients. Exploring to identify client issues occurs by selecting, organizing, and moving miniatur arrangements. The process of putting miniatures and the process of telling miniatures is so much easier for them to express their feelings.

The counselor should take an important role in helping the client continue the rehabilitation in line with the programs provided by the Cure and Care Clinic. 
Counselors can use interventions in counseling so that they can attract clients to make counseling a process that helps them to continue to recover.

The sandtray therapy approach in this study is seen as helping the counselor in the process of building relationships, exploring and understanding what the client is sharing in achieving the goals and objectives of the session. The emerging dynamics of the clusters also play an important role so that clients are comfortable to share with themselves with other members of the group. Therefore, a counselor wishing to use the sandtray therapy approach should attend specific courses or seminars to enhance their skills.

\section{LIMITATIONS AND RECCOMENDATIONS}

The limitation faced by the counselor in this study is related to the dialect or dialect used by the client during the session. It is a challenge when the counselor does not understand what the client wants to say or some of the terms of the language. This may disrupt the travel of the session especially in the exploration process. Counselors can take steps by making some research on the background of the client to learn more about their accent.

Suggestions for future researchers are to make a study of client experiences that have undergone a group counseling session using a sandtray therapy approach. This study is important for researchers to know whether this approach affects clients in helping them undergo a recovery process.

\section{CONCLUSION}

In conclusion, the approach to sandtray therapy needs to be expanded and become one of the approaches used in all Cure and Care Clinics that accommodate adolescents especially. This is because the sandtray therapy approach can help the counselor to explore and understand the client's drug addiction teenager early on. Additionally, the Cure or Care Clinic management or the National Anti-Aging Agency itself can provide good infrastructure so that the sandtray therapy approach can be implemented. The counselor should equip themselves with the skills and knowledge of this approach so that the counselor is more willing and able to conduct the session well.

\section{REFERENCES}

Gooh Mo Lee, Ku Suhaila Ku Johari, ZuriaMahmud, Linda Jamaludin, 2018. The Impact of Sandtray Therapy in Group Counseling towards Children's Self-Esteem, International Journal of Academic Research in Business \& Social Sciences.

Homeyer, L. E \& Sweeney, D. S., 2016. SandtrayTherapy: A Practical Manual. ThirdEdition. Routledge.
Lasimon Bin Matokrem., 2007. Intervensi Dan Peranan Kaunselor Untuk Menjana Kepulihan Klien Sepanjang Hayat. Jurnal Antidadah Malaysia

Merriam, S B., 2009. Qualitative Research: A Guide To Design And Implementation. San Francisco, Ca: Jossey-Bass

Mohamad Isa Amat, et all, 2018. Terapi Psiko-Spiritual Islam Dalam Modul 7 Langkah Kepulihan Dalam Penagihan

Monakes, S., Garza, Y., Wiesner Iii, V. \& Watts, R. E., 2011. Implementing Adlerian Sand Tray Therapy With Adult Male Substance Abuse Offenders: A Phenomenological Inquiry, Journal Of Addictions \& Offender Counseling 31, 94107.

Noor Azniza Ishak, Muhammad Syamsul Mat Zin, Mahmood Nazar Mohamed, Muhammad Dzahir Kasa, Zulkama'azura Zulkarnain Siti Sarah Md. Yusuf, 2013. Intervensi Terapi Kognitif Tingkahlaku Terhadap Kesediaan Berubah Dan Estim Kendiri Penghuni Rumah Pengasih-Kajian Rintis (Pengujian Modul Cbt)

Nur Shakila Ibrarim\& Ku Suhaila Ku Johari, 2015. Aplikasi Terapi Sandtray Dalam Proses Kaunseling, Jurnal Perkama, 19, 121-134.

Ramsey, L.C., 2014. Windows And Bridges Of Sand: Cross-Cultural Counseling Using Sand Tray Methods.Social And Behavioral Sciences, 159, 541-545.

Yin, R. K., 1994. Case Study Research Design And Methods: Applied Social Research And Methods Series. Second Edn. Thousand Oaks, Ca: Sage Publications Inc. 